\title{
Efficacy of Fenfluramine and Norfenfluramine Enantiomers and Various Antiepileptic Drugs in a Zebrafish Model of Dravet Syndrome
}

\author{
Jing $\mathrm{Li}^{1}$ - Maxim Nelis ${ }^{2}$. Jo Sourbron ${ }^{3}$ - Daniëlle Copmans ${ }^{1} \cdot$ Lieven Lagae $^{3}$ - Deirdre Cabooter ${ }^{2}$. \\ Peter A. M. de Witte ${ }^{1}$ (1)
}

Received: 23 February 2021 / Revised: 7 May 2021 / Accepted: 15 May 2021 / Published online: 26 May 2021

(c) The Author(s) 2021

\begin{abstract}
Dravet syndrome (DS) is a rare genetic encephalopathy that is characterized by severe seizures and highly resistant to commonly used antiepileptic drugs (AEDs). In 2020, FDA has approved fenfluramine (FFA) for treatment of seizures associated with DS. However, the clinically used FFA is a racemic mixture (i.e. ( \pm )-FFA), that is substantially metabolized to norfenfluramine (norFFA), and it is presently not known whether the efficacy of FFA is due to a single enantiomer of FFA, or to both, and whether the norFFA enantiomers also contribute significantly. In this study, the antiepileptic activity of enantiomers of FFA (i.e. (+)-FFA and (-)-FFA) and norFFA (i.e. (+)-norFFA and (-)-norFFA) was explored using the zebrafish scnl $\mathrm{Lab}^{-/-}$mutant model of DS. To validate the experimental conditions used, we assessed the activity of various AEDs typically used in the fight against DS, including combination therapy. Overall, our results are highly consistent with the treatment algorithm proposed by the updated current practice in the clinical management of DS. Our results show that (+)-FFA, (-)-FFA and (+)-norFFA displayed significant antiepileptic effects in the preclinical model, and thus can be considered as compounds actively contributing to the clinical efficacy of FFA. In case of (-)-norFFA, the results were less conclusive. We also investigated the uptake kinetics of the enantiomers of FFA and norFFA in larval zebrafish heads. The data show that the total uptake of each compound increased in a time-dependent fashion. A somewhat similar uptake was observed for the (+)-norFFA and (-)-norFFA, implying that the levo/dextrotation of the structure did not dramatically affect the uptake. Significantly, when comparing (+)-FFA with the less lipophilic (+)-norFFA, the data clearly show that the normetabolite of FFA is taken up less than the parent compound.
\end{abstract}

Keywords Dravet syndrome $\cdot$ Zebrafish $\cdot$ Antiepileptic activity $\cdot$ Fenfluramine $\cdot$ Norfenfluramine $\cdot$ Enantiomers

Peter A. M. de Witte

peter.dewitte@kuleuven.be

1 Department of Pharmaceutical and Pharmacological Sciences, Laboratory for Molecular Biodiscovery, University of Leuven (KU Leuven), Herestraat 49, 824, 3000 Leuven, Belgium

2 Department of Pharmaceutical and Pharmacological Sciences, Laboratory for Pharmaceutical Analysis, University of Leuven (KU Leuven), Leuven, Belgium

3 Department of Pediatric Neurology, University Hospitals Leuven, Leuven, Belgium

\section{Introduction}

Dravet syndrome (DS) is a rare, but severe developmental epileptic encephalopathy that begins in infancy $[1,2]$. The first seizures are typically triggered by fever, and are characterized by long-lasting hemiclonic or generalized clonic or tonic-clonic convulsions. Later, the seizures evolve with age, and multiple seizure types may occur, such as focal, atypical absences, and myoclonic seizures. Furthermore, motor dysfunction, behavioural disorder, and cognitive impairment appear [3, 4]. Also increased incidence of mortality is reported in DS patients, especially due to a higher risk of sudden unexpected death [5,6]. Regarding the genetic architecture of DS, a de novo mutation in the gene SCNIA which encodes for an $\alpha$ (pore-forming) subunit of the 
brain voltage gated sodium channel type- $1\left(\mathrm{Na}_{\mathrm{V}} 1.1\right)$, occurs in a large majority of patients [7].

Most DS patients are highly resistant to treatment with commonly used antiepileptic drugs (AEDs). For instance, around $45 \%$ of DS patients in Europe experienced on average more than four tonic-clonic seizures per month, even when treated with polytherapy regimens [8]. Algorithms for management of DS have been proposed by experts in North America [9] and Europe [10] to optimize the treatment outcome of DS patients with a minimal risk for toxicity. The most recent flowchart proposed by Cross and coworkers consists of valproate (VPA) as a first line treatment [10]. When a clear DS diagnosis is given and seizures continue, stiripentol (STP) [with or without clobazam (CLB)] or cannabidiol (CBD) or fenfluramine (FFA) can be added. As an alternative, the administration of topiramate (TPM) or a ketogenic diet may be considered [10].

In 2020, FDA approved FFA for treatment of seizures associated with DS. As a potent releaser and reuptake inhibitor for 5-hydroxytryptamine (5-HT, serotonin), FFA was initially used as an anorectic in polytherapy with phentermine, but was withdrawn from the market in 1997 due to cardiopulmonary side effects at high dosages [10]. However, the successful use of low dosage FFA as an add-on therapy for the treatment of DS was reported by Ceulemans et al. [11, 12] including the achievement of seizure free cases. Later clinical trials have further confirmed the efficacy and safety of FFA in treatment of DS. Importantly, no cardiovascular adverse effects were observed in these trials [1].

Chemically, FFA used in the clinic is a racemic mixture, meaning that equal amounts of left-, and right-handed stereo-isomers (enantiomers) of the chiral molecule are present, i.e. (-)-FFA or levoFFA and (+)-FFA or dexFFA (Fig. 1). In addition, pharmacokinetic investigations have shown that FFA is substantially metabolized to norfenfluramine (norFFA), a $N$-dealkylated derivative of FFA resulting in circulating plasma levels that are similar to or greater than that of FFA itself, in human and animal models [13, 14]. Notably, circulating norFFA also consists of a racemic mixture of (-)-norFFA and (+)-norFFA (Fig. 1). As the various FFA and norFFA enantiomers are endowed with somewhat differing pharmacological profiles involving especially 5 -HT, and type 1 sigma $(\sigma 1)$ receptors $[13,15]$, possibly resulting in a different antiepileptic activity, it is presently not known whether the efficacy of racemic FFA in the treatment of DS is due to a single enantiomer of FFA, or to both, and whether the norFFA enantiomers also contribute significantly.

Zebrafish are vertebrate models with genetic, physiological and CNS features that are highly conserved across vertebrates, including humans. Since zebrafish $s c n l L a b$ is evolutionarily close to the mammalian SCNIA gene [16], a zebrafish scn1Lab double indemnity (didy ${ }^{552}$ ) mutant model has been used to find new medication to treat DS patients [17]. Homozygous scnlLab mutants display spontaneously occurring seizures and brain epileptiform discharges, facilitating their use in phenotype-based screening projects [17].

In this study, the antiepileptic activity of the enantiomers of FFA and norFFA was explored using the zebrafish scn $1 \mathrm{Lab}^{-1-}$ mutant model of DS in behavioral and electrophysiological assays. To validate the experimental conditions used, we explored the activity of a set of AEDs typically used in the fight against DS, including combination therapies. Finally, also the uptake of all four compounds in the larval zebrafish heads as a function of incubation
Fig. 1 The structure of (+)-FFA

(A), (-)-FFA (B), (+)-norFFA

(C) and (-)-norFFA (D)
A

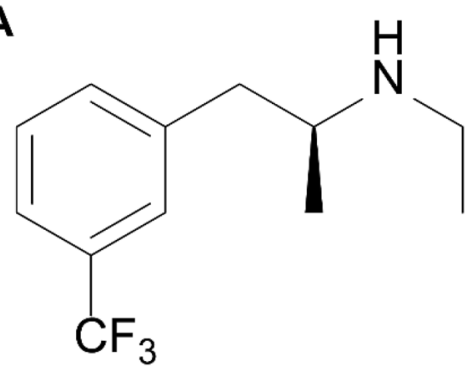

C

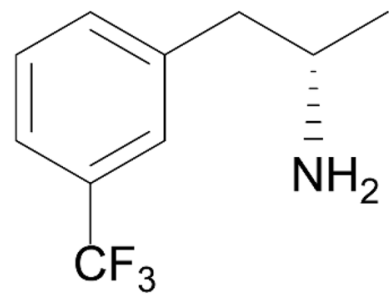

B<smiles>CCN[C@@H](C)Cc1cccc(C(F)(F)F)c1</smiles>

D

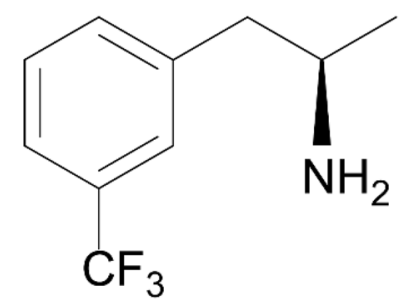


time was assessed using Liquid Chromatography Mass Spectrometry (LC-MS).

\section{Materials and Methods}

\section{Zebrafish Maintenance}

Husbandry conditions of adult wild-type (AB-strain) and scnlLab heterozygous mutant zebrafish (Danio rerio) were as described previously [18]. Fertilized eggs were collected following natural spawning. Then embryos and larvae were sorted and raised in embryo medium $(0.3 \times$ Danieau's solution: $1.5 \mathrm{mM}$ HEPES, $\mathrm{pH}$ 7.6, $17.4 \mathrm{mM} \mathrm{NaCl}, 0.21 \mathrm{mM} \mathrm{KCl}, 0.12 \mathrm{mM} \mathrm{MgSO}_{4}$, $0.18 \mathrm{mM} \mathrm{Ca}\left(\mathrm{NO}_{3}\right)_{2}$ ) in a Peltier-cooled incubator (IPP 260 , Memmert, Schwabach, Germany) at $28{ }^{\circ} \mathrm{C}$, using a 14/10 light/dark cycle. At 6 days post-fertilization ( $6 \mathrm{dpf}$ ) scnl Lab ${ }^{-/-}$mutant larvae were selected by their darker appearance, lack of a swim bladder and slight curvature of the body, as performed before [18].

\section{Compound Preparation}

Valproate (VPA), topiramate (TPM), stiripentol (STP), cannabidiol (CBD), clobazam (CLB), levetiracetam (LEV), carbamazepine (CBZ), and lamotrigine (LTG) were purchased from Sigma-Aldrich. Phenytoin (PHT) was from Acros Organics. ( \pm )-Fenfluramine $[( \pm)$-FFA] was a gift from Prof. Berten Ceulemans (University of Antwerp, Belgium). The enantiomers of FFA and norfenfluramine (norFFA) were provided by Zogenix International (Emeryville, USA). Compounds were dissolved in dimethylsulfoxide (DMSO), and diluted in embryo medium to achieve a final DMSO concentration of $0.1 \% \mathrm{w} / \mathrm{v}$. Embryo medium with $0.1 \% \mathrm{w} / \mathrm{v}$ DMSO served as a vehicle control (VHC).

\section{Toxicity Evaluation}

To evaluate the maximum tolerated concentration (MTC) of the individual compounds, a dozen of WT zebrafish larvae (6 dpf) were individually incubated in single wells of a 96-well plate, and treated with two-fold serial dilutions of the compounds. After $22 \mathrm{~h}$ incubation under standard conditions $\left(28{ }^{\circ} \mathrm{C}, 14 / 10\right.$ light/dark cycle), larvae were individually examined for their touch response, posture, edema, signs of necrosis, morphology, heartbeat rate, and swim bladder condition under the microscope. The MTC was defined as the highest concentration at which a compound did not exert any sign of toxicity in any of the larvae used.

\section{Locomotor Activity Measurement}

WT and homozygous zebrafish larvae (scnl $\mathrm{Lab}^{-/-}$mutants) (6 dpf) were individually positioned in single wells of a 96-well plate, and incubated in $100 \mu \mathrm{L}$ VHC or VHC supplemented with compound or combined compounds for $22 \mathrm{~h}$ at $28^{\circ} \mathrm{C}$ on a $14 / 10 \mathrm{~h}$ light/dark cycle. Then, the plates were placed immediately in an enclosed tracking device (ZebraBox Viewpoint, France), followed by a 30 min chamber habituation and 10 min recording. Locomotor activity over the total tracking period of 10 min was quantified by ZebraLab software (Software Viewpoint, France) using the lardist parameter (total distance in large movements) and $150 \mathrm{bkg}$ (background) as a threshold, as reported previously by our group $[18,19]$. For "small/large movement" and "inact/small movement", a threshold was used of 6.4 and 3.3, respectively. Data were pooled from three or four independent experiments, with at least five larvae for each treatment and 20-30 larvae for each experimental condition, and expressed as "cm" per $100 \mathrm{~s}$.

\section{Local Field Potential Recordings}

WT and homozygous zebrafish larvae (scnlLab ${ }^{-1-}$ mutants) (6 dpf) were treated as described above. After incubation, larvae were immobilized in $2 \%$ low-melting-point agarose (Invitrogen) at room temperature (RT) and the epileptiform activities were measured by noninvasive local field potential (LFP) recording from the skin above the optic tectum (midbrain). The single glass electrode filled with artificial cerebrospinal fluid (ACSF) (124 mM NaCl, $2 \mathrm{mM} \mathrm{KCl}, 2 \mathrm{mM}$ $\mathrm{MgSO}_{4}, 2 \mathrm{mM} \mathrm{CaCl}_{2}, 1.25 \mathrm{mM} \mathrm{KH}_{2} \mathrm{PO}_{4}, 26 \mathrm{mM} \mathrm{NaHCO}_{3}$, and $10 \mathrm{mM}$ glucose) was positioned on the skin above the optic tectum. Each recording lasted for $10 \mathrm{~min}$. Epileptiform activity was quantified by using Clampfit 10.2 software (Molecular Devices Corporation, USA60), as reported previously by our group $[18,19]$.

\section{Measurement of Compound Concentration in Heads}

\section{Extraction Procedure}

WT and homozygous zebrafish larvae (scnlLab ${ }^{-1-}$ mutants) (6 dpf) were treated as described above. After incubation with compounds, larvae were washed and euthanized by exposure to cold Milli-Q water. Then, the heads of larvae were carefully separated under the microscope, and five heads were transferred collectively into one $1.5 \mathrm{~mL}$ Eppendorf tube with acid-washed glass beads (diameter: 710-1180 $\mu \mathrm{M}$, Sigma Aldrich) and $275 \mu \mathrm{L}$ extraction medium (HPLC grade methanol, Sigma Aldrich). Next, the samples were homogenized by $10 \mathrm{~min}$ of ultrasonication (Diagenode Bioruptor Plus, Belgium) at $4{ }^{\circ} \mathrm{C}$. The overall 
ultrasonication process encompassed 10 cycles of $30 \mathrm{~s}$ with pauses of $30 \mathrm{~s}$ in-between with high energy input [20]. After the subsequent centrifugation (14,500 g, $15 \mathrm{~min}), 200 \mu \mathrm{L}$ of supernatant were collected from each tube, and stored in $-80{ }^{\circ} \mathrm{C}$ for further LC-MS processing.

\section{HPLC Instrumentation and Quantification}

Analyses were performed using an Infinity 1200 LC system (Agilent Technologies, Waldbronn, Germany) equipped with an autosampler, binary pump, and a thermostated column oven compartment. An YMC-Triart C18 $(50 \times 2.0 \mathrm{~mm}$; $d_{\mathrm{p}}=1.9 \mu \mathrm{m}$ ) column was utilized for the chromatographic separations at $40{ }^{\circ} \mathrm{C}$. Samples were injected in a volume of $1 \mu \mathrm{L}$ and the flow rate was set to $0.2 \mathrm{~mL} / \mathrm{min}$. The mobile phase consisted of $10 \mathrm{mM}$ ammonium acetate in $\mathrm{H}_{2} \mathrm{O}$ : acetonitrile 75:25 $(v / v)$ and separations were carried out isocratically. The elution time of (-)- and (+)-FFA was $4.1 \mathrm{~min}$, while the elution time of (-)- and (+)-norFFA was $2.6 \mathrm{~min}$. The LC instrument was hyphenated to a mass spectrometer (MS) with a triple quadrupole detector (API 3000, Applied Biosystems, Carlsbad, CA, USA) and equipped with an electrospray ionization source. The MS/MS analysis was conducted in multiple reaction mode (MRM) in positive mode. The MS settings were optimized by direct infusion of compound standards diluted in methanol. The optimal MS parameters are summarized in Table 1.

Quantification was performed through the use of a calibration curve created for each compound separately in blank matrix, which was derived from a pooled set of blank fish heads $(n=40)$. Calibrators consisted of $90 \mu \mathrm{L}$ of blank matrix spiked with $10 \mu \mathrm{L}$ of the corresponding standard dissolved in $\mathrm{MeOH}$ to obtain a concentration range varying between $0.025 \mu \mathrm{M}$ to $7.5 \mu \mathrm{M}$ for (+)-FFA, $0.02 \mu \mathrm{M}$ to $5 \mu \mathrm{M}$ for (-)-FFA, $0.05 \mu \mathrm{M}$ to $10 \mu \mathrm{M}$ for (+)-norFFA, and $0.02 \mu \mathrm{M}$ to $10 \mu \mathrm{M}$ for (-)-norFFA. Ranges consisted of at least 5 concentrations, each of which was analyzed in replicate $(\mathrm{n}=5)$. A weighed least squares (WLS) regression model with $1 / x^{2}$ weighing was utilized such that backcalculated concentrations did not deviate more than $15 \%$ from their nominal value. The final values of the regression coefficients $\left(\mathrm{R}^{2}\right)$ were $0.993,0.998,0.992$, and 0.990 for $(+)$ FFA, (-)-FFA, (+)-norFFA and (-)-norFFA, respectively.
The mean head weight ( \pm S.D.) of a $6 \mathrm{dpf}$ and $7 \mathrm{dpf}$ zebrafish larva was $192 \pm 10 \mu \mathrm{g}$ and $196 \pm 13 \mu \mathrm{g}$, respectively, as measured by weighing three batches of 50 fresh heads after removing excess water with filter paper. The final uptake was calculated according to the method reported by Copmans et al. [21], and expressed as amount/head weight $(\mu \mathrm{g} / \mathrm{g})$.

\section{Statistical Analysis}

The locomotor activity data were analyzed by one-way ANOVA followed by Dunnett's multiple comparison tests. Electrographic brain activity data were analyzed by Kruskal-Wallis testing with Dunn's multiple comparisons. All test were performed in GraphPad Prism 8 software (GraphPad Software, Inc, USA). Significance was calculated only when compound treatment decreased the seizure activity. Significance levels: ${ }^{*} \mathrm{p} \leq 0.05,{ }^{* *} \mathrm{p} \leq 0.01,{ }^{* * *} \mathrm{p} \leq 0.001$, **** $\mathrm{p} \leq 0.0001$.

\section{Results}

\section{Pharmacological Evaluation of the Zebrafish scn $1 \mathrm{Lab}^{-/}$Mutant Model}

To validate the zebrafish scn $1 \mathrm{Lab}^{-/-}$mutant model and the experimental conditions used in this study, we first tested a series of antiepileptic drugs (AEDs) proposed by different treatment algorithms for DS [8-10, 22, 23], including valproate (VPA), racemic fenfluramine $[( \pm)$-FFA], topiramate (TPM), stiripentol (STP), cannabidiol (CBD), clobazam (CLB) and levetiracetam (LEV). In addition, AEDs that should be avoided by DS patients, like carbamazepine (CBZ), phenytoin (PHT) and lamotrigine (LGT) were examined as they target the sodium channel resulting in seizure aggravation [6, 24].

Various concentrations of the AEDs were examined for their adverse effects, allowing a maximum tolerated concentration (MTC) to be determined. MTC is defined as the highest concentration at which the compound did not exert any sign of toxicity in any of the larvae tested. MTC values were determined as $1 \mathrm{mM}$ for VPA, $50 \mu \mathrm{M}$ for $( \pm)$-FFA,

Table 1 Optimized mass settings for FFA and norFFA

\begin{tabular}{llllllllllll}
\hline Compound & Transition (Da) & DP (V) & FP (V) & EP (V) & CE (eV) & CXP (V) & NEB (psi) & CUR (psi) & CAD (psi) & $\begin{array}{c}\text { Heater } \\
\text { gas (L/ } \\
\text { min) }\end{array}$ & $\begin{array}{c}\left.\text { TEM ( }{ }^{\circ} \mathrm{C}\right) \\
\text { IS (V) }\end{array}$ \\
\hline FFA & $232>159$ & 40 & 180 & 10 & 29 & 10 & 8 & 6 & 4 & 7 & 300 \\
norFFA & $204>159$ & 33 & 120 & 10 & 29 & 8 & 9 & 9 & 6 & 4 & 300 \\
\hline
\end{tabular}

$D P$ declustering potential, $F P$ focusing potential, $E P$ entrance potential, $C E$ the collision energy, and $C X P$ the collision cell exit potential, $N E B$ the nebulization gas, CUR the curtain gas, $C A D$ the collision gas, TEM the temperature and $I S$ the ionspray voltage 
$200 \mu \mathrm{M}$ for TPM, $50 \mu \mathrm{M}$ for STP, $6.25 \mu \mathrm{M}$ for CBD, $100 \mu \mathrm{M}$ for CLB, $10 \mathrm{mM}$ for LEV, $50 \mu \mathrm{M}$ for CBZ, $100 \mu \mathrm{M}$ for PHT, and $100 \mu \mathrm{M}$ for LTG. By using these maximal concentrations for all further investigations, we sought to reduce the risk of false positive results to a minimum, which is particularly critical for locomotor activity measurements.

Next, the effect of each of these AEDs as a single treatment on locomotor and brain activities was evaluated by behavioral and electrophysiological assays using the zebrafish scnlLab ${ }^{-1-}$ mutant model. As shown in Fig. 2, VPA elicited a complete rescue of the epileptiform locomotor activity (Fig. 2A, P $\leq 0.0001$ ) and epileptiform brain discharges of the mutant larvae, as monitored by measuring the cumulative duration (Fig. $2 \mathrm{~B}, \mathrm{P} \leq 0.0001$ ) and frequency (Fig. 2C, P $\leq 0.0001$ ).

Of interest, VPA rarely provides adequate seizure control in DS patients, so that it requires the addition of others AEDs as second-line therapies [10], whereas in our hands VPA fully corrected the seizure phenotype of the scnl Lab ${ }^{-/}$mutants. In the clinic, however, VPA shows doselimiting side-effects after prolonged use like fatigue, hair loss and hyperammonemia amongst others [25]. Possibly the relative short treatment of zebrafish used in this study allowed to use an immersion concentration that exceeds the corresponding clinical dose of VPA, resulting in an enhanced efficacy.

Similarly to VPA, $( \pm$ )-FFA (Fig. $2 \mathrm{~A}, \mathrm{P} \leq 0.0001)$ and TPM (Fig. $2 \mathrm{~A}, \mathrm{P} \leq 0.001$ ) not only significantly counteracted the increased locomotor activity observed in scnl $\mathrm{Lab}^{-1-}$ mutants, but also dramatically attenuated the frequency of epileptiform events (Fig. $2 \mathrm{C}, \mathrm{P} \leq 0.001$ and $\mathrm{P} \leq 0.05$, respectively), resulting in a decrease of cumulative duration (Fig. $2 \mathrm{~B}, \mathrm{P} \leq 0.0001$ for $( \pm$ )-FFA, $\mathrm{P} \leq 0.01$ for TPM).

By contrast, STP, CBD, CLB and LEV failed to rescue both the hyper-locomotor activity and brain epileptic discharges of scnlLab ${ }^{-1-}$ mutants (Fig. 2). Also, as expected, no inhibitory effects could be observed with CBZ, PHT and LTG treatments (Fig. 2).

As STP, CBD and ( \pm )-FFA are typically combined in the clinic with VPA for second line treatment [10], we further validated the $s c n l \mathrm{Lab}^{-/-}$mutant model by exploring the activity of this combination treatment. Since VPA as a single treatment at $1 \mathrm{mM}$ completely reduced the read-outs to the level exhibited by $\mathrm{AB}$ control larvae, we modified its concentration to $250 \mu \mathrm{M}$. This concentration exerted a limited and statistically non-significant effect on the locomotor activity and epileptiform brain discharges of the mutant larvae (Fig. 3).

Significantly, the combination of VPA $(250 \mu \mathrm{M})$ and STP $(50 \mu \mathrm{M})$ turned out to effectively alter the locomotor activity and decrease the epileptiform discharges of the mutant larvae, whereas the single treatments were not active (Fig. 3A-C).

Furthermore, investigating the combination outcome of VPA $(250 \mu \mathrm{M})$ and $( \pm)$-FFA, the concentration of the latter compound was reduced from $50 \mu \mathrm{M}$ (MTC) to $3.13 \mu \mathrm{M}$. This concentration continued to induce a significant effect
A

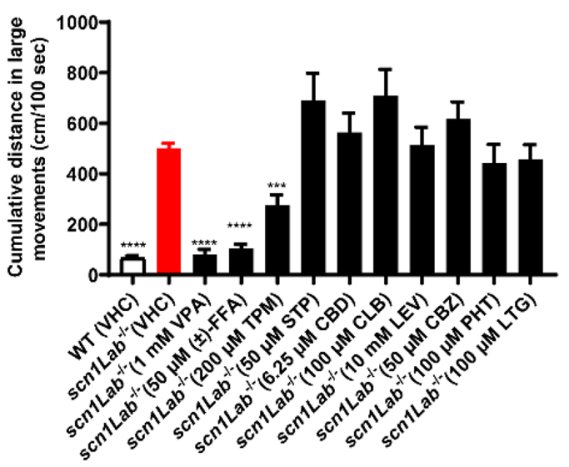

B

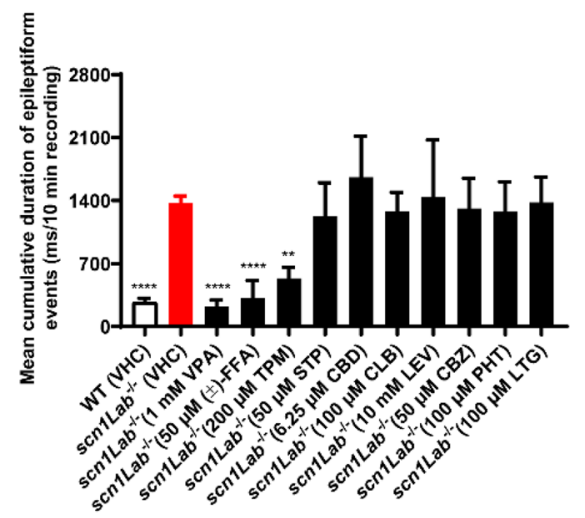

C

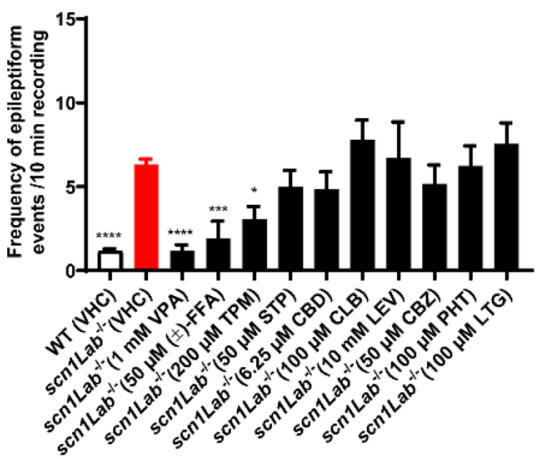

Fig. 2 Behavioral (A) and electrophysiological (B, C) antiepileptic activity of valproate (VPA), $( \pm)$ fenfluramine $[( \pm)$-FFA], topiramate (TPM), stiripentol (STP), cannabidiol (CBD), clobazam (CLB), levetiracetam (LEV), carbamazepine (CBZ), phenytoin (PHT), and lamotrigine (LTG) in the zebrafish scnl Lab ${ }^{-/-}$mutant model. (A) Locomotor activity of larvae pre-exposed to antiepileptic drugs (AEDs) for $22 \mathrm{~h}$. Data were assessed over the total tracking period of $10 \mathrm{~min}$ and expressed as cm/100 s. Results were pooled from 3-4 independent experiments, with 207 larvae for each of the VHC-treated groups, and 22-31 larvae for each AED-treated group. (B, C) Noninvasive local field potential (LFP) recordings from the optic tectum of larvae pre-exposed to antiepileptic drugs (AEDs) for $22 \mathrm{~h}$. Epileptiform discharges are quantified by the cumulative duration (mean \pm SEM) (B) and frequency (mean \pm SEM) (C) of events per 10-min recording. With 72 larvae for the VHC-treated group, 10-15 larvae for each AED-treated group. Statistical analysis: one-way ANOVA with Dunnett's multiple comparison test (locomotor assay), Kruskal-Wallis testing with Dunn's multiple comparisons (LFP measurements). Significance levels: ${ }^{*} \mathrm{p} \leq 0.05,{ }^{* *} \mathrm{p} \leq 0.01,{ }^{* * *} \mathrm{p} \leq 0.001,{ }^{* * * *} \mathrm{p} \leq 0.0001 . W T$ wide type, $V H C$ vehicle 


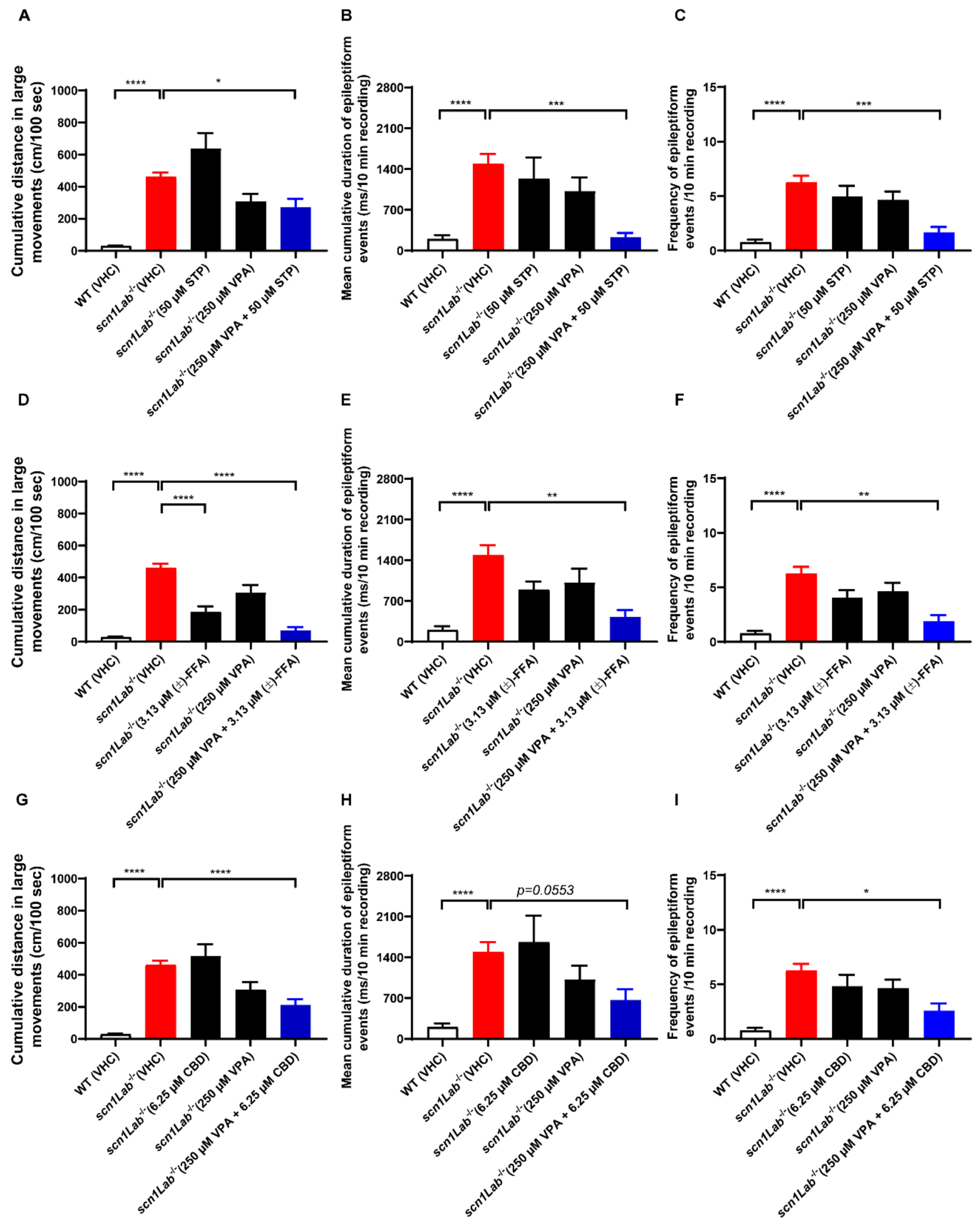


४Fig. 3 Behavioral (A, D, G) and electrophysiological (B, C, E, F, H, I) antiepileptic activity of combination treatment (colored in blue) of valproate (VPA) with stiripentol (STP) (A-C), $( \pm)$ fenfluramine $[( \pm)$-FFA] (D-F), and cannabidiol (CBD) $(\mathbf{G}-\mathbf{I})$ in the zebrafish scn$1 \mathrm{Lab}^{-/-}$mutant model. (A, D, G) Locomotor activity of larvae preexposed to antiepileptic drugs (AEDs) for $22 \mathrm{~h}$. Data were assessed over the total tracking period of $10 \mathrm{~min}$ and expressed as $\mathrm{cm} / 100 \mathrm{~s}$. Results were pooled from 3-4 independent experiments, with 120 larvae for each of the VHC-treated groups, and 20-30 larvae for each AED-treated group. (B, C, E, F, H, I) Noninvasive local field potential (LFP) recordings from the optic tectum of larvae pre-exposed to antiepileptic drugs (AEDs) for $22 \mathrm{~h}$. Epileptiform discharges are quantified by the cumulative duration (mean \pm SEM) $(\mathbf{B}, \mathbf{E}, \mathbf{H})$ and frequency (mean \pm SEM) $(\mathbf{C}, \mathbf{F}, \mathbf{I})$ of events per 10-min recording. With 23 larvae for the VHC-treated group, 12-14 larvae for each AED-treated group. Statistical analysis: one-way ANOVA with Dunnett's multiple comparison test (locomotor assay), Kruskal-Wallis testing with Dunn's multiple comparisons (LFP measurements). Significance levels: ${ }^{*} \mathrm{p} \leq 0.05,{ }^{* *} \mathrm{p} \leq 0.01,{ }^{* * *} \mathrm{p} \leq 0.001,{ }^{* * * *} \mathrm{p} \leq 0.0001$. WT wild type, $V H C$ vehicle

on the locomotor activity but not on the epileptiform brain discharges of the mutant larvae (Fig. 3D-F). The combined compounds diminished the locomotor activity of mutant larvae treated with $3.13 \mu \mathrm{M}( \pm)$-FFA (single treatment) by more than half on average, although the difference observed was statistically not significant (Fig. 3D). The LFP results further show that the combination of VPA and $( \pm)$-FFA was highly effective in reducing the epileptiform discharges of the mutant larvae, whereas the single treatments were not (Fig. 3E, F).

Finally, when VPA $(250 \mu \mathrm{M})$ was combined with CBD (6.25 $\mu \mathrm{M})$, the VPA + CBD-treatment showed a clear effect on the locomotor and LFP results obtained with the mutant larvae as compared to the single treatments that were not active (Fig. 3G-I).

As far as alternatives for second line treatment are concerned [10], i.e. TPM and CLB, only the former exhibited a pronounced therapeutic activity in the $s c n 1 \mathrm{Lab}^{-1-}$ mutant model. Noticeably, CLB was previously proven to be ineffective in the DS zebrafish mutant model [26]. Although CLB has also been suggested as a first-line drug by the North American consensus panel, it typically only displays efficacy in DS patients when combined with VPA and STP [9]. Whether CLB therefore classifies as a true false negative in the scn $1 \mathrm{Lab}^{-1-}$ mutant model is yet to be investigated into more detail, for instance by exploring its additional activity in combination with VPA and STP, as suggested by Cross et al. [10].

LEV has been categorized as a third-line drug for DS by the North American consensus panel [9], but is not mentioned in the treatment options by Cross et al. [10]. As a matter of fact, there is limited clinical evidence regarding its efficacy in the clinic, with retrospective studies demonstrating low responder rates in DS patients [23]. Significantly, the compound also failed to suppress the seizure-like activity of $s c n 1 \mathrm{Lab}^{-/-}$mutants in this study, as shown before [17].

\section{Determination of the Time-Dependent Concentration of Enantiomers of FFA and norFFA in Zebrafish Head}

In order to investigate the uptake kinetics of the enantiomers of FFA and norFFA in larval zebrafish heads, we immersed larvae in solutions of the individual compounds at their MTC for $30 \mathrm{~min}, 4 \mathrm{~h}$ and $22 \mathrm{~h}$. Next, the compounds present in extracts of the heads were quantified by LC-MS analysis. The data depicted in Fig. 4 show that the total uptake (amount of compound/head weight) of each enantiomer of FFA and norFFA increased in a time-dependent fashion.

A somewhat similar uptake was observed for the $(+)$-norFFA and (-)-norFFA enantiomers, implying that the levo/dextrotation of the structure did not dramatically affect the uptake. Conversely, a direct comparison between $(+)$-FFA and its (-)-enantiomer is hard to draw as different immersion concentrations were used due to the different MTCs of the respective compounds.

\section{Antiepileptic Activity of Enantiomers of FFA and norFFA in the Zebrafish scn $1 \mathrm{Lab}^{-/-}$Mutant Model}

As uptake of compounds in larval heads was maximal after $22 \mathrm{~h}$, we proceeded to use this prolonged incubation condition to explore the pharmacological activity of the FFA and norFFA enantiomers, as performed previously $[18,19]$. To investigate the potency of the compounds to prevent the epileptiform activity exhibited by the scn $1 \mathrm{Lab}^{-/-}$mutants, they were first examined by a behavioral assay, at a wide range of concentrations. As illustrated in Fig. 5, all enantiomers of FFA and norFFA effectively counteracted abnormal locomotor activity of mutant larvae at their MTC, 1/4 MTC and 1/40 MTC [1/20 MTC for (-)-FFA], whereas lower concentrations were not active. In addition, all drugs displayed their maximum effects at their respective 1/4 MTCs (Fig. 5, $\mathrm{P} \leq 0.0001)$.

Subsequently, we examined the effect of the compounds on the epileptiform discharges of the mutant larvae by recording local field potentials (LFP) of the brain. Representative traces of brain activity during the recordings are shown in Fig. 6. As depicted in Fig. 7, all compounds except for (-)-norFFA significantly reduced the frequency and cumulative duration of the epileptiform events, at least at their MTC. The results therefore confirm most of the results obtained using the locomotor assay, although some concentration-related discrepancies exist, especially in the case of (-)-norFFA. A different outcome between the two assays has also been reported by others [17, 19, 27], possibly 
Fig. 4 The total uptake of (+)-FFA (A), (-)-FFA (B), (+)-norFFA $(\mathbf{C})$ and (-)-norFFA (D) in the larvae head after different exposure times (30 min, $4 \mathrm{~h}$ and $22 \mathrm{~h}$ ). The concentration in the head of larvae pre-exposed to (+)-FFA (A), (-)-FFA (B), (+)-norFFA (C) and (-)-norFFA (D) at their respective MTCs for $30 \mathrm{~min}, 4 \mathrm{~h}$ and $22 \mathrm{~h}$, separately, and total uptake of compound = compound concentration/head weight. With 5 larvae heads for each sample, and 5 replicates for a total of 25 larvae heads per treatment. Statistical analysis: one-way ANOVA with Dunnett's multiple comparison test. Significance levels: ${ }^{*} \mathrm{p} \leq 0.05$, ${ }^{* *} \mathrm{p} \leq 0.01,{ }^{* * *} \mathrm{p} \leq 0.001$, **** $\mathrm{p} \leq 0.0001$. WT wild type, $V H C$ vehicle, $F F A$ fenfluramine, norFFA norfenfluramine
A

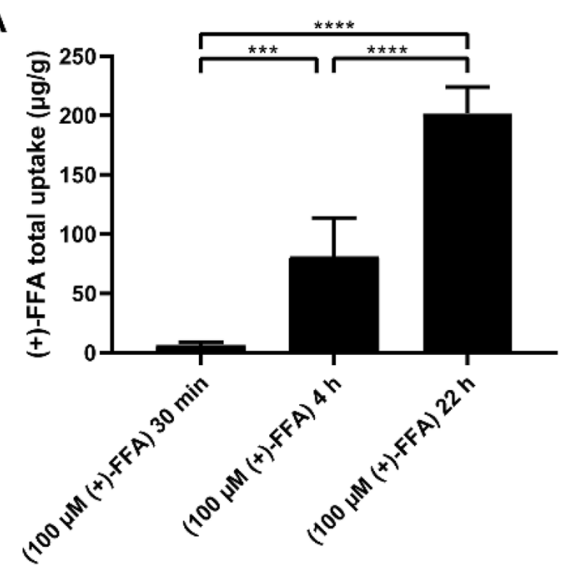

C

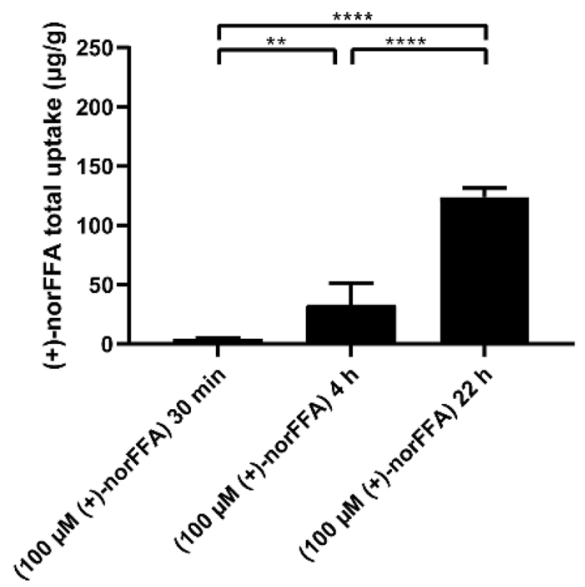

B

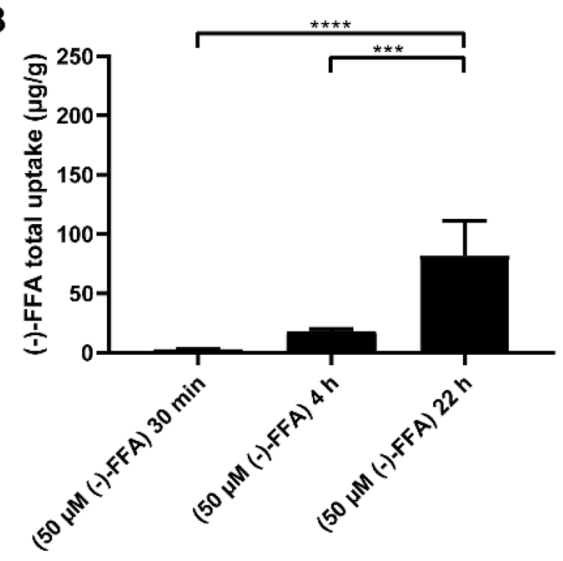

D

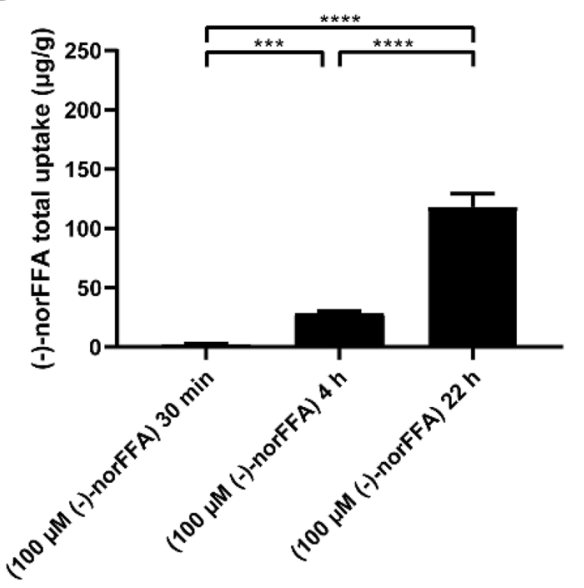

the result of some extra peripheral off-target effects of compounds affecting the locomotor read-out.

\section{Discussion}

Overall, our results mirror well the order of multiple treatment options proposed by the updated current practice in management of DS [10]. Notably, a similar validation of the $\operatorname{scn} 1 \mathrm{Lab}^{-/-}$mutant zebrafish DS model was previously performed, using a shorter incubation protocol than present in this study [17, 28]. However, to our knowledge, this is the first study that shows the activity of combined AED therapy, thereby further corroborating the zebrafish DS model. Moreover, the outcome of this study seems to indicate that (+)FFA and especially (+)-norFFA exhibited inhibitory profiles that were more consistent and concentration-dependent than the (-)-enantiomers, for both locomotor and LFP read-outs.

Surprisingly, a substantial increase in concentrations could still be observed in the $4-22 \mathrm{~h}$ time window. To the best of our knowledge, this study is the first to quantify the uptake of any drug compound in heads of zebrafish larvae as a function of time, and consequently it is not possible to conclude whether FFA and norFFA are actually unique in this respect. However, a certain parallel is apparent with the clinical condition, where accumulation of (+)-FFA and $(+)$-norFFA in humans typically follows a step-wise increase to steady state concentrations after long-term repetitive drug administration [29].

Other studies reported the uptake of compounds in heads and brain of larval zebrafish after $1 \mathrm{~h}$ incubations [20,30]. Of interest, when measuring head uptake of haloperidol (clog P value: 4.3 ) or diphenhydramine (clog P value: 3.3 ) after incubating $5 \mathrm{dpf}$ zebrafish larvae for $1 \mathrm{~h}$ with $15 \mu \mathrm{g} /$ $\mathrm{mL}$ of the compounds, the recovered concentrations were $21.6 \mu \mathrm{g} / \mathrm{g}$ and $115.5 \mu \mathrm{g} / \mathrm{g}$, respectively [30]. As the lipophilicity of compounds is a crucial determinant for the uptake in body and brain tissue [20,31], and the clog P values of FFA and norFFA are 3.47 and 2.68, respectively, the aforementioned data are in line with the results obtained after 1-4 h incubations in this study. Significantly, when comparing (+)-FFA with the less lipophilic (+)-norFFA, the data clearly show that the nor-metabolite of FFA is taken up less than the parent compound.

Obviously, the activity of the compounds is determined by their relative uptake in brain tissue in combination 
A

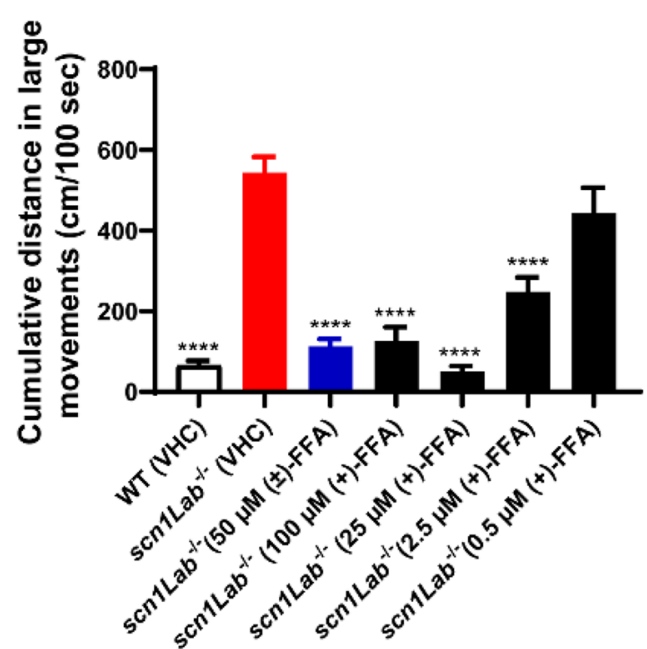

C

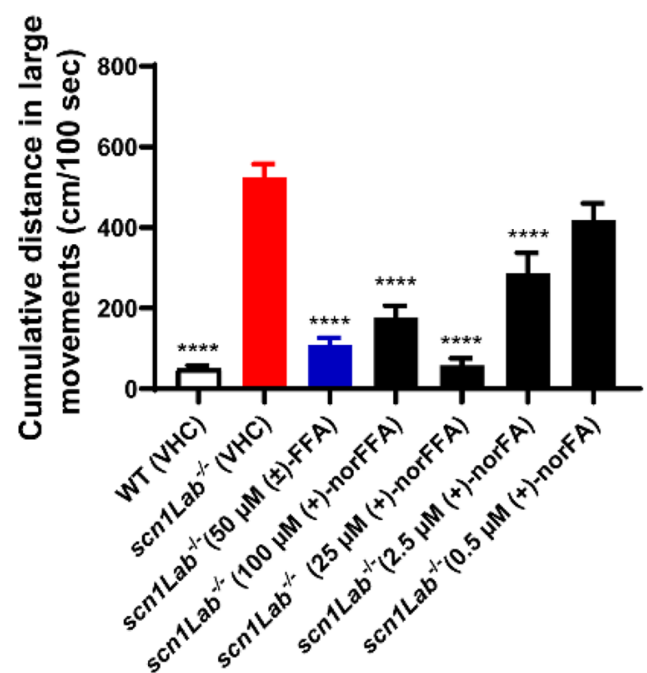

Fig. 5 Behavioral antiepileptic activity of (+)-FFA (A), (-)-FFA (B), (+)-norFFA (C) and (-)-norFFA (D) in the zebrafish scn$1 \mathrm{Lab}^{-/-}$mutant model, and ( \pm )-FFA (colored in blue, A-D), used as a positive control. (A-D) Locomotor activity of larvae pre-exposed to different concentration of enantiomers of FFA and norFFA for $22 \mathrm{~h}$. Data were assessed over the total tracking period of $10 \mathrm{~min}$

with their underlying molecular mechanisms. Of importance, an increasing number of reports has indicated that low 5-HT (serotonin) brain levels are involved in epileptogenesis and/or seizure propagation [32, 33], and a 5-HT deficit was also reported in the heads of homozygous scn $1 \mathrm{Lab}^{-/-}$mutants [19]. Significantly, as shown in Table 2, both enantiomers of FFA and norFFA are potent substrates for 5-HT transporter proteins, with $\mathrm{EC}_{50}$ values ranging from 52 to $287 \mathrm{nM}$. Other effects of the enantiomers relate to potent serotonin uptake inhibition and agonistic effects on 5- $\mathrm{HT}_{2}$ subtype receptors (Table 2) [13, 34]. Effects on dopamine and norepinephrine uptake and release have also been documented, although a wide range of potencies were found for the different FFA and norFFA
B

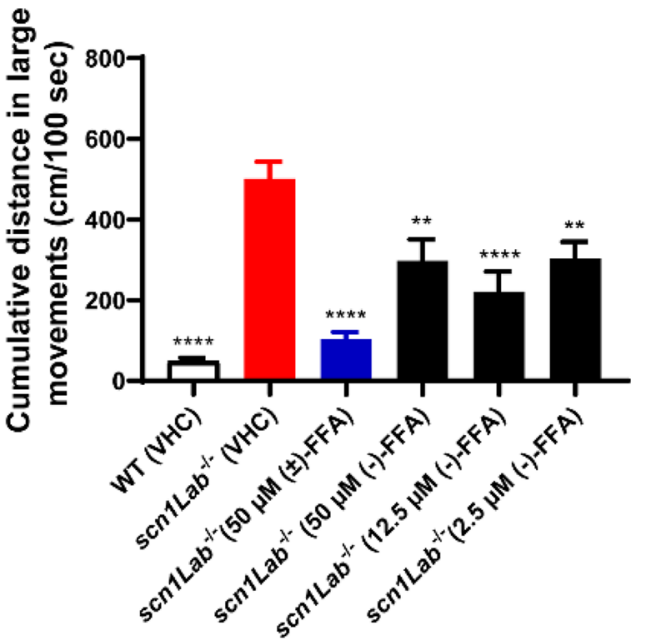

D

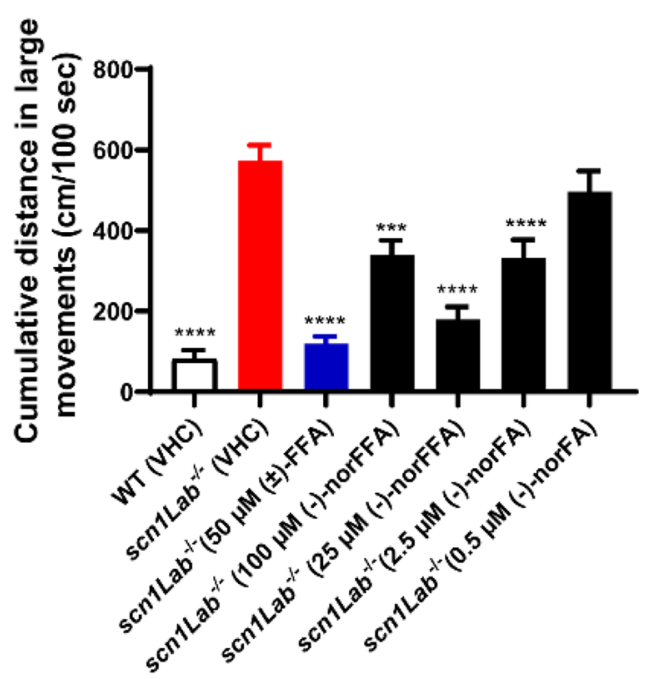

and expressed as $\mathrm{cm} / 100 \mathrm{~s}$. Results were pooled from 3-4 independent experiments, with 67-75 larvae for each VHC-treated group, and 21-28 larvae for each compound-treated group. Statistical analysis: one-way ANOVA with Dunnett's multiple comparison test. Significance levels: ${ }^{*} \mathrm{p} \leq 0.05,{ }^{* *} \mathrm{p} \leq 0.01,{ }^{* * *} \mathrm{p} \leq 0.001,{ }^{* * * *} \mathrm{p} \leq 0.0001$. WT wild type, $V H C$ vehicle, FFA fenfluramine, norFFA norfenfluramine

enantiomers (Table 2). In addition, the (+)-enantiomers of FFA and norFFA can diminish glutamatergic N-methyl-Daspartate (NMDA) neurotransmission through disrupting its association with type 1 sigma $(\sigma 1)$ receptors, thereby acting as highly potent $\sigma 1 \mathrm{R}$ antagonists [15]. Unfortunately, the activity of the individual enantiomers of FFA and its metabolites were not examined in the latter study. Significantly, using similar conditions as in this study (i.e. $25 \mu \mathrm{M}, 22 \mathrm{~h}$ incubation), the racemic mixture ( \pm )-FFA was found to exert its anti-seizure activity in DS zebrafish mainly through its modulation of $5-\mathrm{HT}_{2 \mathrm{C}}-\mathrm{R}, 5-\mathrm{HT}_{1 \mathrm{D}}-\mathrm{R}$, sigma-1-R and possibly 5- $\mathrm{HT}_{2 \mathrm{~A}}-\mathrm{R}$ [18], thereby confirming the aforementioned data obtained with mammalian cell-based assays. 
WT (VHC)

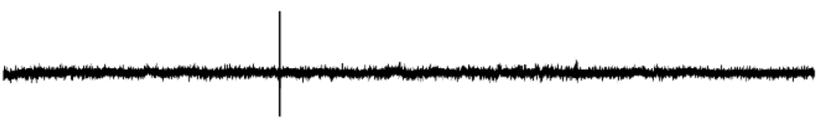

${\operatorname{scn} 1 L a b^{-/-}}_{(100 \mu \mathrm{M}(+)-F F A)}$

$\operatorname{scn} 1 \mathrm{Lab}^{-/-}(100 \mu \mathrm{M}(+)$-norFFA $)$

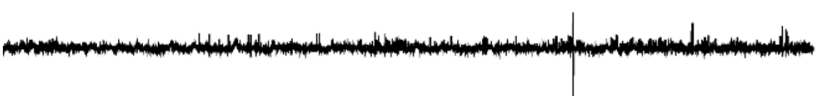

$0.5 \mathrm{mV}$

$2 \min$

Fig. 6 Representative local field potential recordings. Ten-min noninvasive local field potential (LFP) recordings from the optic tectum of larvae pre-exposed to (+)-FFA, (-)-FFA, (+)-norFFA and

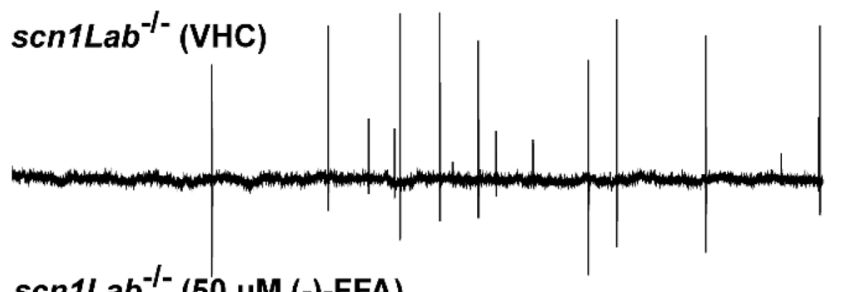

$\operatorname{scn} 1 L^{-1 /-}(50 \mu \mathrm{M}(-)-\mathrm{FFA})$

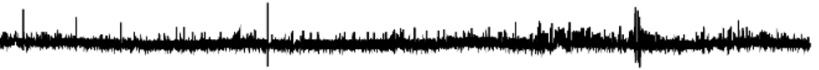

scn1Lab ${ }^{-/-}(100 \mu \mathrm{M}(-)-$ norFFA)

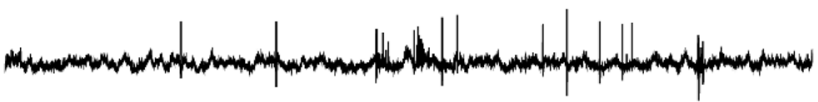

(-)-norFFA for $22 \mathrm{~h}$. WT wild type, $V H C$ vehicle, $F F A$ fenfluramine, norFFA norfenfluramine
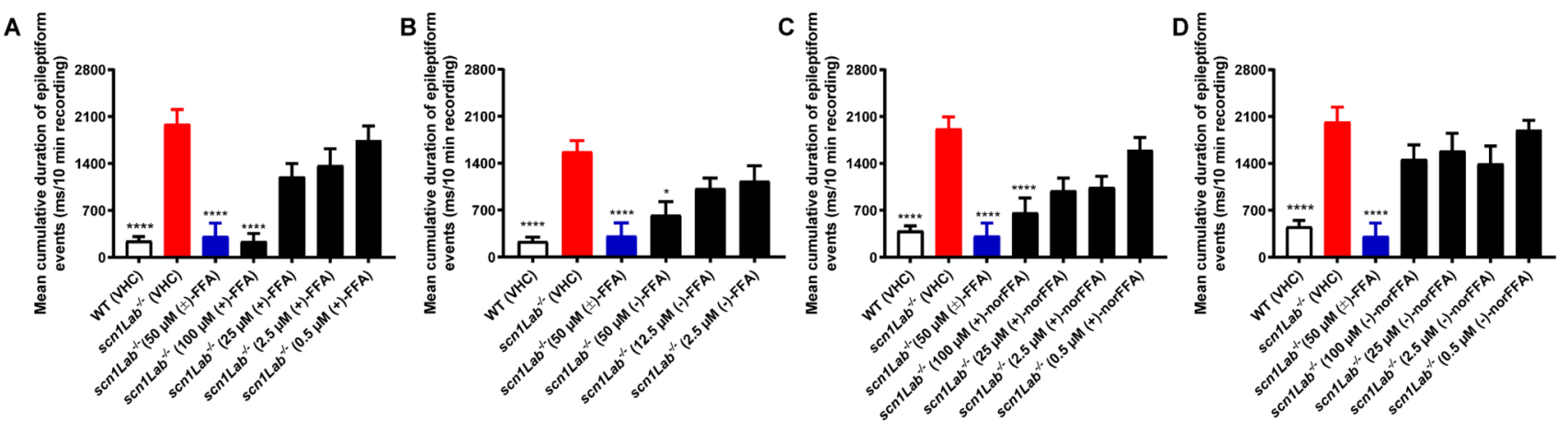

$\mathrm{E}$

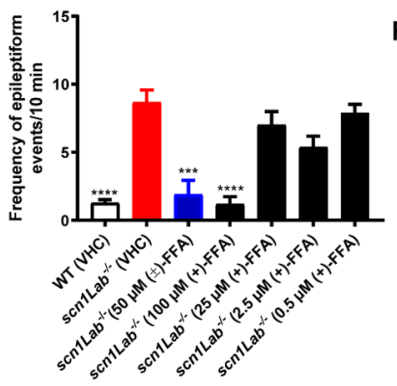

$F$

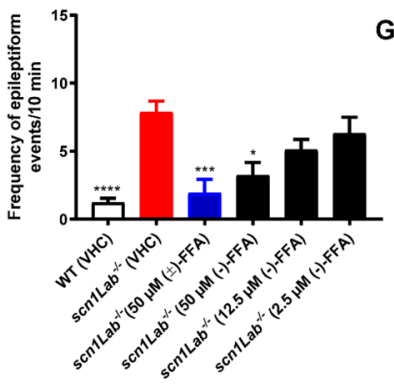

Fig. 7 Electrophysiological antiepileptic activity of (+)-FFA (A, E), $(-)$-FFA $(\mathbf{B}, \mathbf{F}),(+)$-norfFA $(\mathbf{C}, \mathbf{G})$ and $(-)$-norfFA $(\mathbf{D}, \mathbf{H})$ in the scnl Lab ${ }^{-l-}$ mutant model, and ( \pm )-FFA (colored in blue, A-H) used as a positive control. (A-H) Noninvasive local field potential (LFP) recordings from the optic tectum of larvae pre-exposed to (+)-FFA, $(-)$-FFA, (+)-norFFA and (-)-norFFA for $22 \mathrm{~h}$. Epileptiform discharges are quantified by the cumulative duration (mean \pm SEM)

The data available therefore show that the enantiomers of FFA and norFFA possess somewhat different pharmacological potencies on a subset of receptors that have
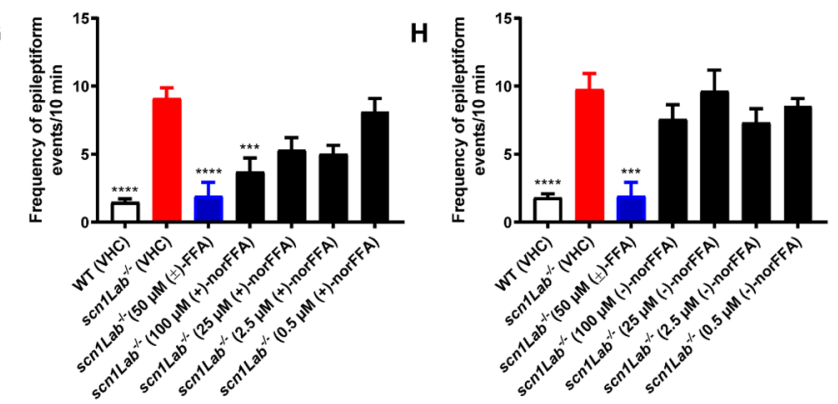

(A-D) and frequency (mean \pm SEM) $(\mathbf{E}-\mathbf{H})$ of events per 10-min recording. With 27-45 larvae for each VHC-treated group, and 10-16 larvae for each compound-treated group. Statistical analysis: Kruskal-Wallis testing with Dunn's multiple comparisons. Significance levels: ${ }^{*} \mathrm{p} \leq 0.05,{ }^{* *} \mathrm{p} \leq 0.01,{ }^{* * *} \mathrm{p} \leq 0.001,{ }^{* * * *} \mathrm{p} \leq 0.0001$. WT wild type, $V H C$ vehicle, $F F A$ fenfluramine, norFFA norfenfluramine

been implicated in their anti-epileptic activity. However, in view of the larval head concentrations of the individual compounds found in this study, one would not anticipate 
Table 2 Potency of enantiomers of FFA and norFFA

\begin{tabular}{|c|c|c|c|c|c|c|c|c|c|}
\hline \multirow[t]{2}{*}{ Compound } & \multicolumn{3}{|c|}{$\mathrm{EC}_{50}$ values $(\mathrm{nM})$ for release } & \multicolumn{3}{|c|}{$\mathrm{K}_{\mathrm{i}}$ values (nM) for uptake inhibition } & \multicolumn{3}{|c|}{$\begin{array}{l}\mathrm{K}_{\text {act }} \text { values }(\mathrm{nM}) \text { for } 5-\mathrm{HT}_{2} \text { receptor } \\
\text { subtypes }\end{array}$} \\
\hline & DA & $\mathrm{NE}$ & $5-\mathrm{HT}$ & $\mathrm{DA}$ & $\mathrm{NE}$ & $5-\mathrm{HT}$ & $\overline{5-\mathrm{HT}_{2 \mathrm{~A}}}$ & $5-\mathrm{HT}_{2 \mathrm{~B}}$ & $5-\mathrm{HT}_{2 \mathrm{C}}$ \\
\hline$(+)$-FFA & $>10,000$ & $302 \pm 20$ & $51.7 \pm 6.1$ & $>20,000$ & $1286 \pm 52$ & $150 \pm 5$ & $>10,000$ & $379 \pm 70$ & $362 \pm 64$ \\
\hline (-)-FFA & $>10,000$ & $>10,000$ & $147 \pm 19$ & $>20,000$ & $7187 \pm 559$ & $714 \pm 31$ & $5279 \pm 587$ & $1248 \pm 252$ & $360 \pm 91$ \\
\hline (+)-norFFA & $924 \pm 112$ & $72.7 \pm 5.4$ & $59.3 \pm 2.4$ & $2312 \pm 87$ & $205 \pm 19$ & $214 \pm 9$ & $630 \pm 141$ & $18.4 \pm 5.3$ & $13 \pm 2.4$ \\
\hline (-)-norFFA & $>10,000$ & $474 \pm 40$ & $287 \pm 14$ & $19,194 \pm 1,048$ & $2052 \pm 297$ & $1175 \pm 89$ & $1565 \pm 190$ & $357 \pm 105$ & $18 \pm 3.5$ \\
\hline
\end{tabular}

Adapted from Rothman et al. [13, 34]

any major difference in outcome for both locomotor and LFP read-outs. Moreover, as the pharmacological fingerprint of (-)-norFFA is not substantially different from the one of (-)-FFA, it is rather surprising that the former compound exerted a less conclusive inhibitory activity in the DS zebrafish model. Evidently, the slightly conflicting results might be explained by enantiomers' relative affinities for zebrafish proteins differing to those for their mammalian counterparts. However, the mechanism-of-action of the antiepileptic effect of FFA is multi-dimensional, also involving $\sigma 1$-receptors and possibly other targets, further complicating the interpretation of the finding. Clearly more investigations are needed to better understand the relationship between the pharmacology of the compounds and their respective antiepileptic activities against DS.

Taken together, our study is the first to validate the $s c n$ $1 \mathrm{Lab}^{-1-}$ mutant model by using a combined treatment of AEDs, further supporting the application of the zebrafishbased model as a rapid screening platform to find precision medicine for DS, and possibly for other difficult-to-treat epilepsies. In addition, our results show that $(+)$-FFA, $(-)$ FFA and (+)-norFFA displayed significant antiepileptic effects in the preclinical model, and thus can be considered as compounds actively contributing to the clinical efficacy of FFA. In case of (-)-norFFA, the results were less conclusive. Whether this inconsistency is related to a different pharmacological fingerprint is presently unexplored and warrants further investigation.

Acknowledgements We sincerely thank Prof. Berten Ceulemans (University of Antwerp, Belgium) for providing ( \pm )-FFA, and Zogenix (USA) for providing enantiomers of FFA and norFFA.

Author Contributions JL: Conceptualization, Investigation, Methodology, Data curation, Writing — original draft; MN: Methodology, Data curation; JS: Methodology, Writin—review and editing; DC: Methodology, Data curation; LL and DC: Supervision, Writing-review and editing; PAMW: Data curation, Supervision, Writing-review and editing.

Funding Jing Li is funded by a Chinese Scholarship Council doctoral fellowship (File No.201606250020).
Data Availability All data generated or analyzed during this study are included in this published article.

\section{Declarations}

Conflict of interest Lieven Lagae and Peter A. M. de Witte receive consultancy honoraria from Zogenix (USA).

Ethical Approval All zebrafish experiments carried out were approved by the Ethics Committee of the University of Leuven (approval numbers 027/2017 and 023/2017) and by the Belgian Federal Department of Public Health, Food Safety, and Environment (approval number LA1210199).

Open Access This article is licensed under a Creative Commons Attribution 4.0 International License, which permits use, sharing, adaptation, distribution and reproduction in any medium or format, as long as you give appropriate credit to the original author(s) and the source, provide a link to the Creative Commons licence, and indicate if changes were made. The images or other third party material in this article are included in the article's Creative Commons licence, unless indicated otherwise in a credit line to the material. If material is not included in the article's Creative Commons licence and your intended use is not permitted by statutory regulation or exceeds the permitted use, you will need to obtain permission directly from the copyright holder. To view a copy of this licence, visit http://creativecommons.org/licenses/by/4.0/.

\section{References}

1. Lagae L, Sullivan J, Knupp K, Laux L, Polster T, Nikanorova M, Devinsky O, Cross JH, Guerrini R, Talwar D, Miller I, Farfel G, Galer BS, Gammaitoni A, Mistry A, Morrison G, Lock M, Agarwal A, Lai WW, Ceulemans B (2019) Fenfluramine hydrochloride for the treatment of seizures in Dravet syndrome: a randomised, double-blind, placebo-controlled trial. Lancet 394:2243-2254. https://doi.org/10.1016/S0140-6736(19)32500-0

2. Dravet C (2011) Dravet syndrome history. Dev Med Child Neurol 53:1-6. https://doi.org/10.1111/j.1469-8749.2011.03964.x

3. Khan S, Al Baradie R (2012) Epileptic encephalopathies: an overview. Epilepsy Res Treat 2012:403592. https://doi.org/10.1155/ 2012/403592

4. Lagae L, Brambilla I, Mingoranc A, Gibson E, Battersby A (2018) Quality of life and comorbidities associated with Dravet syndrome severity: a multinational cohort survey. Dev Med Child Neurol 60:63-72. https://doi.org/10.1111/dmcn.13591 
5. Cooper MS, Mcintosh A, Crompton DE, McMahon JM, Schneider A, Farrell K, Ganesan V, Gill D, Kivity S, Lerman-Sagie T, McLellan A, Pelekanos J, Ramesh V, Sadleir L, Wirrell E, Scheffer IE (2016) Mortality in Dravet syndrome. Epilepsy Res 128:43-47. https://doi.org/10.1016/j.eplepsyres.2016.10.006

6. Wirrell EC, Nabbout R (2019) Recent advances in the drug treatment of Dravet syndrome. CNS Drugs 33:867-881. https://doi. org/10.1007/s40263-019-00666-8

7. Claes L, Ceulemans B, Audenaert D, Smets K, Löfgren A, DelFavero J, Ala-Mello S, Basel-Vanagaite L, Plecko B, Raskin S, Thiry P, Wolf NI, Van Broeckhoven C, De Jonghe P (2003) De novo SCN1A mutations are a major cause of severe myoclonic epilepsy of infancy. Hum Mutat 21:615-621. https://doi.org/10. 1002/humu.10217

8. Aras LM, Isla J, Mingorance-Le Meur A (2015) The European patient with Dravet syndrome: results from a parent-reported survey on antiepileptic drug use in the European population with Dravet syndrome. Epilepsy Behav 44:104-109. https://doi.org/ 10.1016/j.yebeh.2014.12.028

9. Wirrell EC, Laux L, Donner E, Jette N, Knupp K, Meskis MA, Miller I, Sullivan J, Welborn M, Berg AT (2017) Optimizing the diagnosis and management of Dravet syndrome: recommendations from a North American consensus panel. Pediatr Neurol 68:18-34. https://doi.org/10.1016/j.pediatrneurol.2017.01.025

10. Cross JH, Caraballo RH, Nabbout R, Vigevano F, Guerrini R, Lagae L (2019) Dravet syndrome: treatment options and management of prolonged seizures. Epilepsia 60:S39-S48. https://doi.org/ 10.1111/epi.16334

11. Ceulemans B, Boel M, Leyssens K, Van Rossem C, Neels P, Jorens PG, Lagae L (2012) Successful use of fenfluramine as an add-on treatment for Dravet syndrome. Epilepsia 53:1131-1139. https://doi.org/10.1111/j.1528-1167.2012.03495.x

12. Ceulemans B, Schoonjans A-S, Marchau F, Paelinck BP, Lagae L (2016) Five-year extended follow-up status of 10 patients with Dravet syndrome treated with fenfluramine. Epilepsia 57:e129e134. https://doi.org/10.1111/epi.13407

13. Rothman RB, Clark RD, Partilla JS, Baumann MH (2003) (+)-Fenfluramine and its major metabolite, (+)-norfenfluramine, are potent substrates for norepinephrine transporters. J Pharmacol Exp Ther 305:1191-1199. https://doi.org/10.1124/jpet.103. 049684

14. Marchant NC, Breen MA, Wallace D, Bass S, Taylor AR, Ings RMJ, Campbell DB, Williams J (1992) Comparative biodisposition and metabolism of ${ }^{14} \mathrm{C}-( \pm)$-fenfluramine in mouse, rat, dog and man. Xenobiotica 22:1251-1266. https://doi.org/10.3109/ 00498259209053154

15. Rodríguez-Muñoz M, Sánchez-Blázquez P, Garzón J (2018) Fenfluramine diminishes NMDA receptor-mediated seizures via its mixed activity at serotonin $5 \mathrm{HT}_{2 \mathrm{~A}}$ and type 1 sigma receptors. Oncotarget 9:23373-23389. https://doi.org/10.18632/oncotarget. 25169

16. Novak AE, Taylor AD, Pineda RH, Lasda EL, Wright MA, Ribera AB (2006) Embryonic and larval expression of zebrafish voltagegated sodium channel $\alpha$-subunit genes. Dev Dyn 235:1962-1973. https://doi.org/10.1002/dvdy.20811

17. Baraban SC, Dinday MT, Hortopan GA (2013) Drug screening in Scn1a zebrafish mutant identifies clemizole as a potential Dravet syndrome treatment. Nat Commun 4:2410. https://doi.org/10. 1038/ncomms 3410

18. Sourbron J, Smolders I, de Witte P, Lagae L (2017) Pharmacological analysis of the anti-epileptic mechanisms of fenfluramine in scnla mutant zebrafish. Front Pharmacol 8:191. https://doi.org/ 10.3389/fphar.2017.00191

19. Sourbron J, Schneider H, Kecskés A, Liu Y, Buening EM, Lagae L, Smolders I, de Witte P (2016) Serotonergic modulation as effective treatment for Dravet syndrome in a zebrafish mutant model. ACS Chem Neurosci 7:588-598. https://doi.org/10.1021/ acschemneuro.5b00342

20. Kislyuk S, Van den Bosch W, Adams E, de Witte P, Cabooter D (2018) Development of a sensitive and quantitative capillary LC-UV method to study the uptake of pharmaceuticals in zebrafish brain. Anal Bioanal Chem 410:2751-2764. https://doi. org/10.1007/s00216-018-0955-4

21. Copmans D, Orellana-Paucar AM, Steurs G, Zhang Y, Ny A, Foubert K, Exarchou V, Siekierska A, Kim Y, De Borggraeve W, Dehaen W, Pieters L, de Witte PAM (2018) Methylated flavonoids as anti-seizure agents: Naringenin 4',7-dimethyl ether attenuates epileptic seizures in zebrafish and mouse models. Neurochem Int 112:124-133. https://doi.org/10.1016/j.neuint.2017.11.011

22. Frampton JE (2019) Stiripentol: a review in Dravet syndrome. Drugs 79:1785-1796. https://doi.org/10.1007/ s40265-019-01204-y

23. Wirrell EC (2016) Treatment of Dravet syndrome. Can J Neurol Sci 43:S13-S18. https://doi.org/10.1017/cjn.2016.249

24. Wilmshurst JM, Gaillard WD, Vinayan KP, Tsuchida TN, Plouin P, Van Bogaert P, Carrizosa J, Elia M, Craiu D, Jovic NJ, Nordli D, Hirtz D, Wong V, Glauser T, Mizrahi EM, Cross JH (2015) Summary of recommendations for the management of infantile seizures: task force report for the ILAE commission of pediatrics. Epilepsia 56:1185-1197. https://doi.org/10.1111/epi.13057

25. Duman B, Can KC, Ağtaş-Ertan E, Erdoğan S, İlhan RS, Doğan Ö, Kumbasar H, Çamsarı UM (2019) Risk factors for valproic acid induced hyperammonemia and its association with cognitive functions. Gen Hosp Psychiatry 59:67-72. https://doi.org/10.1016/j. genhosppsych.2019.05.005

26. Eimon PM, Ghannad-Rezaie M, De Rienzo G, Allalou A, Wu Y, Gao M, Roy A, Skolnick J, Yanik MF (2018) Brain activity patterns in high-throughput electrophysiology screen predict both drug efficacies and side effects. Nat Commun. https://doi.org/10. 1038/s41467-017-02404-4

27. Zhang Y, Vanmeert M, Siekierska A, Ny A, John J, Callewaert G, Lescrinier E, Dehaen W, de Witte PAM, Kaminski RM (2017) Inhibition of glutamate decarboxylase (GAD) by ethyl ketopentenoate (EKP) induces treatment-resistant epileptic seizures in zebrafish. Sci Rep 7:7195. https://doi.org/10.1038/ s41598-017-06294-w

28. Farooq Shaikh M, Wykes RC, Malin Abdullah J, Baraban SC, Griffin A, Hamling KR, Hong S, Anvar M, Lee LP (2018) Preclinical animal models for Dravet syndrome: seizure phenotypes. Comorbidities Drug Screen Front Pharmacol 1:573. https://doi. org/10.3389/fphar.2018.00573

29. Christensen JD, Yurgelun-Todd DA, Babb SM, Gruber SA, Cohen BM, Renshaw PF (1999) Measurement of human brain dexfenfluramine concentration by $19 \mathrm{~F}$ magnetic resonance spectroscopy. Brain Res 834:1-5. https://doi.org/10.1016/S0006-8993(99) 01441-9

30. Fleming A, Diekmann H, Goldsmith P (2013) Functional characterisation of the maturation of the blood-brain barrier in larval zebrafish. PLoS ONE 8:e77548. https://doi.org/10.1371/journal. pone. 0077548

31. Long K, Kostman SJ, Fernandez C, Burnett JC, Huryn DM (2019) Do zebrafish obey lipinski rules? ACS Med Chem Lett 10:10021006. https://doi.org/10.1021/acsmedchemlett.9b00063

32. Maia GH, Brazete CS, Soares JI, Luz LL, Lukoyanov NV (2017) Serotonin depletion increases seizure susceptibility and worsens neuropathological outcomes in kainate model of epilepsy. Brain Res Bull 134:109-120. https://doi.org/10.1016/j.brainresbull. 2017.07.009

33. Bagdy G, Kecskemeti V, Riba P, Jakus R (2007) Serotonin and epilepsy. J Neurochem 100:857-873. https://doi.org/10.1111/j. 1471-4159.2006.04277.x 
34. Rothman RB, Baumann MH (2002) Therapeutic and adverse actions of serotonin transporter substrates. Pharmacol Ther 95:73-88. https://doi.org/10.1016/S0163-7258(02)00234-6

Publisher's Note Springer Nature remains neutral with regard to jurisdictional claims in published maps and institutional affiliations. 